\title{
EMOTICONS IN TRANSACTIONAL AND INTERACTIONAL EXCHANGES: SOCIAL NETWORKING CHITCHAT VERSUS WORKING NEGOTIATION ${ }^{21}$
}

\author{
Carmen Maíz-Arévalo, Universidad Complutense de Madrid \\ Email: cmaizare@ucm.es
}

\begin{abstract}
Emoticons are ordinarily linked to more colloquial computer-mediated exchanges such as informal emails, chats, comments on social networking sites, etc. In these genres, the interactional function of language is also predominant even if there can also be transactional elements. The question rises whether more transactional and formal exchanges make a similar use of emoticons. This paper aims to compare the use of emoticons in two contrastive datasets of computer-mediated communication where either the interactional or transactional function predominates to find out whether emoticons are used as much in transactional as in interactional encounters and whether they perform the same functions.
\end{abstract}

Keywords: computer-mediated communication, emoticons, interactional, transactional function of language.

Resumen: En general, los emoticonos se asocian a contextos de carácter informal (mails informales, chats, redes sociales, etc.). En estos géneros, predomina la función interactiva del lenguaje incluso cuando hay cierta transacción. Esto nos lleva a plantearnos si los emoticonos tienen las misma frecuencia de uso y sirven para desempeñar las mismas funciones en aquellos intercambios mediados por ordenador de carácter más formal. El objetivo de este estudio es comparar el uso de los emoticonos en dos bases de datos: una de carácter interactivo frente a otra transaccional y ver si la frecuencia de uso y las funciones desempeñadas son equiparables.

Palabras clave: comunicación mediada por ordenador, emoticonos, interacción, función transaccional del lenguaje.

\section{INTRODUCTION}

On the whole, emoticons or 'smileys' are ordinarily related by users to more colloquial computer-mediated exchanges such as informal emails, chats, comments on social networking sites, etc. In these genres, the interactional function of language is predominant

21 The present research forms part of a project financed by the Spanish Ministry of Science and Innovation. The reference has been omitted to preserve the anonymity of the reviewing process. 
even if there can also be transactional elements. However, the question rises whether more transactional and formal exchanges make a similar use of emoticons. The present paper aims to compare the use of emoticons in two contrastive corpora of computer-mediated communication where either the interactional or transactional function predominates. More specifically, I intend to answer the following research questions: (i) Are emoticons used as much in interactional as in transactional CMC encounters? And (ii) Do they perform the same functions? It is expected that emoticons will be more frequent in the interactional than the transactional exchanges. Likewise, it is hypothesized that they will perform different pragmatic functions. The rest of the paper is structured as follows: section 2 presents the theoretical framework, attending to different aspects such as defining the interactionaltransactional cline, speech act theory and emoticons. Section 3 focuses on the methodology, describing in detail each of the datasets employed, as well as the participants involved. The fourth section presents the data analysis. For the sake of clarity, this section is divided into two sub-sections, each of them dealing with each of the research questions initially posed. Finally, section five offers the conclusions, limitations of the present study and pointers to future research.

\section{THEORETICAL FRAMEWORK}

\subsection{Interactional versus transactional functions of language and speech act theory}

According to Brown and Yule (1983: 1), transactional language expresses "content", the task in hand whereas interactional language has the function of "expressing social relations and personal attitudes". However, it is clear that both functions are rarely found in isolation and most communication partakes of both in different degrees (Hewitt 2002), with extreme examples at the very end of both ends of the cline.

Finally, it should also be mentioned that speech acts (Searle 1969) can obviously be performed in both transactional and interactional communications. Speech act theory is amply well known to require a fully detailed description here. Suffice it to say that I will be following Searle's (1969) familiar classification of speech acts into five main categories:

(a) Assertives: speech acts that commit a speaker to the truth of the expressed proposition

(b) Directives: speech acts aimed at getting the addressee to take a specific action, e.g. requests

(c) Commissives: commit the speaker to some future action, e.g. promises and threats

(d) Expressives: express the speaker's attitudes and emotions towards the proposition, e.g. apologies

(e) Declaratives: are the speech acts that can change the reality in accord with the proposition of the declaration -i.e. given the appropriate felicity conditions, e.g. pronouncing someone husband and wife.

Some speech acts are more likely to be found when interaction prevails over transaction. For example, expressive speech acts (e.g. compliments, apologies, wishes, concerns, etc.) are to be more expected (albeit not necessarily so) in more interactive exchanges whereas 
others like directives (e.g. requests, commands, suggestions, etc.) may appear more often in exchanges whose main aim is transactional.

Despite its critiques, speech act theory still proves a valuable analytic tool. In this regard, I subscribe to Dresner and Herring's (2010) and Maíz-Arévalo's (in press) opinion that, in order to find out the function of emoticons, it is essential to start by looking at the illocutionary force of the speech act they escort.

\subsection{What are emoticons?}

While face-to-face communication relies on different channels such as the auditory, the gestural, the visual, etc., computer-mediated communication (CMC henceforth) typically makes use of just the visual channel (except when webcams are employed). However, "there is ample evidence that users compensate textually for missing auditory and gestural cues, and that CMD [computer mediated discourse] can be richly expressive" (Herring 2003: 615). These "cues" in CMC have been described as oralisation marks aimed at substituting for key elements of face-to-face communication like intonation or kinesics (Yus 2011). Emoticons are just one of the myriad of typographic possibilities users have at hand, together with others like the repetition of letters (e.g. to add emphasis), capitalization (e.g. to indicate shouting) and other strategies like the use of abbreviations and acronyms.

Despite being more salient than really frequent, emoticons have received a great deal of attention among researchers, as shown by the extensive literature devoted to their study (Crystal 2001; Derks et al. 2004, 2008; Dresner and Herring 2010; Hancock 2004; Lo 2008; Maíz-Arévalo and Santamaría 2013; Walther and D’Addario 2001; among many others). Yet, "little is known about the functional range of emoticons" (Vandergriff 2013: 1). Previous research has pointed out to their functions as boosters of group rapport (Derks et al. 2008; Golato and Taleghani-Nikazm 2006; Hancock 2004 or Walther and D'Addario 2001), expressions of politeness, e.g. as face-saving strategies (Darics (2010), Golato and Taleghani-Nikazm (2006) or markers of illocutionary force (Dresner and Herring 2010). As argued by Maíz-Arévalo (in press):

In any case, emoticons are far from simple additions to the message but perform a core communicative function just as intonation does in oral communication. Consequently, they cannot be dismissed as whimsical and playful cues but regarded (and analysed) as an integral part of the transmitted multimodal message.

\section{METHODOLOGY}

This section describes the two datasets ${ }^{22}$ employed in the current study: an interactional-based dataset (ID henceforth) and a transactional or task-based dataset (TD hereafter), as well as the participants involved in each of them. In both cases, interaction was asynchronous and all the participants held a hybrid relation -i.e. they knew one another

22 The term "corpus" has been purposely avoided given the limited number of words of the current datasets. "Corpus" is considered appropriate when referring to larger datasets such as the British National Corpus, for example. 
both online and offline (Yus 2011). Likewise, it is also important to mention that all the data employed are naturally-occurring and were not elicited for the purpose of research. This, as will be explained later, poses both advantages and disadvantages. Thus, whilst all the data are spontaneous and naturally produced, there are certain imbalances. In any case, there was an attempt to equal the two datasets as much as possible so that they were actually comparable, as will be explained below. Finally, and for the sake of clarity, this section has been divided into two subsections dealing with the description of each dataset and its corresponding set of participants involved.

\subsection{The Interactional dataset (ID)}

The first dataset consists of a set of fifty-four exchanges posted on Facebook's semipublic "wall". This dataset is described as interactional since it is geared towards a more interactional extreme of the interactional-transactional continuum where communication takes place between friends and acquaintances that post their comments on the wall for the pleasure of communicating, reinforcing their social relations and expressing their personal attitudes. More specifically, this set encompasses a total of 6,215 words. As for the participants involved, there is a mixture of native speakers of English (mostly US and UK speakers) but also non-native speakers with a very proficient, quasi-native level of English. In all the exchanges, English is used as a lingua franca (with incidental examples in other languages like Spanish or Hindi). It is more difficult, however, to determine the exact number of participants since the very nature of Facebook allows friends of friends (depending on the users' privacy options) to take part in the exchanges. As for their age range, it spans from their mid-thirties to their early forties.

\subsection{The Transactional dataset (TD)}

The second set consists of the exchanges taking place between classmates in an e-forum targeted to discuss and negotiate their views whilst carrying out a common textual analysis demanded by the lecturer. Students were demanded to analyse a set of multimodal texts and write a collective report. However, they were told to carry out their collective negotiation and analysis -prior to the actual writing of the report -online rather than face-to-face, and by means of a forum. The dataset thus consists of their process of negotiation. The very nature of the task makes it more bound to include more transactional than interactional elements. Initially, the second dataset consisted of the six e-forums produced by 11 master's students. However, this rendered a total of 25,354 words and it was rejected as being too unbalanced with respect to the ID. Hence, in an attempt to balance both datasets, only one of the e-forums was randomly chosen, comprising 8,325 words. Still, there was a slight numeric imbalance. However, it was only apparent since inspection of the data reveals that the task-based activity at hand makes participants include long lists with their raw analysis, which contributes to extend the number of words. This is illustrated by example (1) below, where an excerpt of such a list is reproduced: 
(1) volume $1->$ the prince volume $2 \rightarrow$ Snow White vectors (Im not sure about this) $->$

1) his body leaned to kiss her

2) his hand pointing to the ground

3) his legs (leaned)

2005:

Text: (same analysis as yours)

Image:

volume $1 \rightarrow$ prince

volume $2 \rightarrow$ Snow White

vectors $\rightarrow$

1) leaned to kiss Snow White

2) Hands leaned on the coffin (...)

As for the participants involved, it represents a twofold limitation of the study. On the one hand, the abovementioned need to select just one e-forum limited the number of participants to three, all of them non-native speakers of English. However, two of them had an extremely proficient, quasi-native level of English ${ }^{23}$. Being international students from very different nationalities ${ }^{24}$, they all used English as a lingua franca and there are no isolated examples in other languages. The second limitation concerns the gender of the participants, since all the students in the class were female. For this reason, and although male users also appear in the ID, only those emoticons employed by female users were considered in an attempt to balance both corpora. As for their age, they are slightly younger than the participants in ID, since they are in their late twenties and early thirties. Table (1) below sums up the similarities and differences between both datasets:

\begin{tabular}{|l|l|l|}
\hline & \multicolumn{1}{|c|}{$\begin{array}{c}\text { Interactional dataset } \\
\text { (ID) }\end{array}$} & \multicolumn{1}{|c|}{$\begin{array}{c}\text { Transactional dataset } \\
\text { (TD) }\end{array}$} \\
\hline Type of data & Naturally occurring & Naturally occurring \\
\hline Timing & Asynchronous & Asynchronous \\
\hline Participants' relation & Hybrid & Hybrid \\
\hline $\mathrm{N}^{\circ}$ of words & 6,215 & 8,325 \\
\hline $\mathrm{N}^{\circ}$ of participants & Undetermined & Three \\
\hline Participant's gender & Male and female & Just female \\
\hline Participant's age & Mid-30s to early 40s & Late 20s to early $30 \mathrm{~s}$ \\
\hline
\end{tabular}

Table 1. Similarities and differences between the datasets.

23 C2 according to the Common European Framework of Reference for Languages (2001).

24 There were Egyptian, Russian, Korean, Romanian, Polish, Iranian and Spanish students. 
Finally, it is important to mention that all the data were carefully edited to avoid any personal references like names or images and thus preserve the participants' anonymity and privacy (Kozinets 2010). Thus, names were either substituted for "user" in the case of ID and a culturally-appropriate pseudonym in the case of TD, where the number of participants was wholly controlled.

\section{DATA ANALYSIS}

As mentioned in the introduction, this paper is aimed at answering two research questions: (i) Are emoticons used as much in interactional as in transactional CMC encounters? And (ii) Do they perform the same functions? For the sake of clarity, this section is divided into two sub-sections, each of them dealing with each of the research questions initially posed.

\subsection{Frequency of use: ID vs. TD}

Table 2 below offers a global overview of the frequency of use of emoticons in both datasets. Each set is divided into two columns, where the first column displays the percentage of use within the set of the different emoticons and the second one the total number of instances per type of emoticon in each set.

\begin{tabular}{|l|l|l|l|l|}
\hline \multicolumn{1}{|c|}{ Type of emoticon } & \multicolumn{2}{c|}{$\begin{array}{c}\text { Interactional corpus } \\
\%(\mathrm{n}=\mathbf{2 4})\end{array}$} & \multicolumn{2}{c|}{ Transactional corpus (n=89) } \\
\hline Smiley [] & $62.5 \%$ & $(\mathrm{n}=15)$ & $27 \%$ & $(\mathrm{n}=24)$ \\
\hline Sad face [L] & $12.5 \%$ & $(\mathrm{n}=3)$ & $0 \%$ & $(\mathrm{n}=0)$ \\
\hline Wink [;-)] & $12.5 \%$ & $(\mathrm{n}=3)$ & $14.6 \%$ & $(\mathrm{n}=13)$ \\
\hline Laughter [:-D] & $8.4 \%$ & $(\mathrm{n}=2)$ & $41.5 \%$ & $(\mathrm{n}=37)$ \\
\hline Tongue out [:-p] & $4.2 \%$ & $(\mathrm{n}=1)$ & $2.2 \%$ & $(\mathrm{n}=2)$ \\
\hline Emoji (happy face) $\left[{ }^{\wedge \wedge}\right]$ & $0 \%$ & $(\mathrm{n}=0)$ & $12.3 \%$ & $(\mathrm{n}=11)$ \\
\hline Thinking emoticon [:^)] & $0 \%$ & $(\mathrm{n}=0)$ & $1.2 \%$ & $(\mathrm{n}=1)$ \\
\hline Tired emoticon [(=_=)] & $0 \%$ & $(\mathrm{n}=0)$ & $1.2 \%$ & $(\mathrm{n}=1)$ \\
\hline TOTAL & $100 \%$ & 24 & $100 \%$ & 89 \\
\hline
\end{tabular}

Table 2. Frequency of emoticons in both datasets

In regard to global frequency, the first remarkable difference is that the total number of emoticons in the TD almost triples that of the ID. However, and to avoid the effect of the different number of words in both datasets $(6,215$ vs. 8,325$)$, a word frequency was also carried out for both sets. Thus, if each emoticon is considered as a "word" to be counted within the total amount of words in each dataset, the frequency is rather telling. In ID, for every 100 words, 0.38 are emoticons whereas in TD, for every 100 words, 1.06 are emoti- 
cons, which -against expectations- doubles their frequency in the more transactional set. This frequency is illustrated by example (2) below, which is a complete post by one of the participants, where she accompanies every single utterance by different emoticons such as laughter, smileys, a wink and a final emoji:

(2) We've uploaded it at the same time hehe :D:D

Yes, I haven't included in the first two set of images any of the things we mentioned in Task $3 \mathrm{~J}$

Thank you for uploading Task 3 as well ;)

I'll put them together in 1 file and tomorrow we can proofread everything :D

Good night ${ }^{\wedge \wedge}$

Quite interestingly too, the number of emoticons in TD progressively increases by the end of the forum, probably because students feel rapport has already been built throughout their collaborative task and they intend to keep it that way. The profusion of emoticons towards the final posts of the forum is illustrated by examples (2) above and (3), which reproduces the four final posts in the forum by two of the participants:

(3) [Participant 1]:

Hey!

I've included all the changes you mentioned in this document along with my changes.

I removed the repeated parts from task 2 .So, now they're only mentioned once in task 3.

I have only included the correction in red and I've deleted the previous word/sentence.

I'll be waiting for your comments as well;)

$\mathrm{AH}$, and it's snowing :D:D It's sooo beautiful:D

[Participant 1] (on second thoughts)

I forgot to mention that the yellow highlights have to be deleted.

[Participant 2]

$\mathrm{Ok}$, girls. So this is the final version of the document. I hope everything is ok.

[Participant 1]

Ok perfect ;) thanks a $\operatorname{lot}^{\wedge \wedge}$

There is no easy answer to why the frequency of use in TD exceeds that of ID. Possible reasons might involve the younger age of the participants in TD, which may also account for the fact that they employ a more varied array of emoticons such as emoji ${ }^{25}$, thinking or tired emoticons. Another plausible reason might lie in the more private nature of the Moodle e-forum as opposed to the semi-public milieu of Facebook, where participants might be more cautious when posting their message in the ignorance of who might eventually read it. It could also be due to a combination of these two factors, or others which have not been considered. What is at stake, however, is the fact that transaction might be the ultimate aim of the e-forum but interaction is crucial in its good development and eventual success, as

25 According to Wikipedia: Emoji (Japanese: 絵文字(えもじ) are the ideograms or smileys used in Japanese electronic messages and webpages, the use of which is spreading outside Japan. http://en.wikipedia.org/wiki/ Emoji 
participants are well aware of. In fact, given the need for a good rapport in order to carry out the task successfully, interaction might be playing an even more important role in TD as opposed to ID, where the good rapport is taken for granted, since most of the participants are friends -if just Facebook friends.

In regard to the frequency of the different types of emoticons used in both sets, it can be observed that smileys overwhelmingly lead the way in ID (62.5\%) whilst laughter is the most frequent in TD (41.5\%). Once again, there is no easy explanation for this. However, it can be argued that both smiles and laughter are not that far apart (as opposed, for instance, to more differing emoticons such as sad faces) and might be being used interchangeably in both datasets (see 4.2. for their functions).

When comparing both datasets, winking faces do not pose a big difference in frequency (12.5\% and $14.6 \%$ respectively). Sad faces, however, are completely absent in TD (versus $12.5 \%$ in ID), mainly because the students participating in the forum rarely mention their own sad feelings, which seems to be the core role played by this emoticon, commonly employed with expressive speech acts where the interlocutors confess their sad feelings towards something, as illustrated by the following examples taken from Maíz-Arévalo (2014):

(4) User 1 (m): Thanks to everyone for last night. You're the best.

User 2 (f): I went looking for the GLOBE in the rain and got lost! Sorry to miss it :-( User 1 (m): Oh dear!

In (4), User 2 (female) has missed a farewell party because she got lost on her way there. Her expressive speech act (apology) is accompanied by a sad face, expressing her sadness about it. The whole "sad" mood of the exchange is perfectly captured by User 1, who sympathises by uttering “oh dear!" In (5), User 2 also accompanies her expression of sympathy towards User 1's accident with a sad face, indicating how sad and sorry she is about it.

(5) User 1 (f): Foot is fractured now, got a cast, and crutches!

User 2 (f): Ow! That's not good :-( Try to rest although I know that's easier said than done!

The last emoticon which is commonly used by both groups is the tongue-out one-i.e. :-p. Not surprisingly, and giving its mocking effect, its frequency is slightly higher in ID $(4.2 \%)$, where participants are friends (if just Facebook friends) and the use of mock impoliteness is more acceptable than among the students of TD (2.2\%), who are just starting to build their relationship and rapport and may not be willing to risk it by excessively mocking one another (Haugh and Bousfield 2012).

Finally, there are three emoticons which are exclusively used by the TD participants, namely, emoji $(\wedge \wedge)$, the thinking emoticon $(: /)$ and the tired one $\left(=\_=\right)$. However, out of these three, only the first one is remarkably more frequent $(12.3 \%)$ and its use might be due to the participants' younger age and their knowledge of emoji (a relatively new fashion). The other two emoticons appear just once each and their frequency is thus far from relevant.

In summary, it can be argued that even in a more transactionally oriented type of communication, interaction plays a crucial role. Rapport building becomes a central aspect, especially in a collaborative task like the one at hand. This might explain why emoticons -a feature typically associated with more informal, interactional exchanges-are remarkably more frequent in the TD dataset than its mostly interactional counterpart. As already 
mentioned, however, other reasons such as the more private environment of the TD or the participants' younger age might be affecting this frequency.

The unexpected results led me to carry out informal interviews with two of the three participants in TD so as to ascertain what their motivations for using such a great deal of emoticons might have been. Interestingly enough, their first reaction was surprise since they were unaware that their use of emoticons had been so high. They were well aware that these typographic signs are frequently used in interactional encounters such as chats, informal emails or social networking sites like Facebook or Tuenti, but not in other more academic settings like this collaborative forum where they had been involved. When asked for their motives to accompany their speech acts by emoticons, their common answer was that "it sounded nicer and friendlier". They also added comments like the following, which clearly shows the importance of rapport and emotions even in more transactional exchanges:

I think that writing online can be cold and sound harsher than intended. By simply adding a little emoticon, I feel like I'm adding the "human touch".

Sometimes I find myself slightly annoyed by the cold tone of some messages I receive, maybe it wasn't the intention of the writer to be distant or to sound rude, but I can't help perceiving that "coldness". Emoticons or laughter like "haha" can help it sound more polite and friendly.

\subsection{Functions performed by emoticons in ID and TD}

This section intends to answer the second research question. To this purpose, the relation between the speech acts used and the function(s) performed by its accompanying emoticon will be explored in the coming paragraphs.

Prior research has already proven that emoticons (despite their misleading name ${ }^{26}$ ) do not simply serve to express emotions but can also perform other functions like building or boosting rapport and as politeness strategies -i.e. as face-saving strategies. On the one hand, face-saving can be aimed at the addressee in an attempt to mitigate face-threatening acts such as a directive. On the other, face-saving can be targeted not only at the addressee but simultaneously at the addresser's own face when producing self-demeaning speech acts like apologies.

Inspection of the two datasets at hand reveals that emoticons can in fact be used to:

(i) Boost rapport among interlocutors

(ii) Save face (addresser's and addressee's)

(iii) Enhance the expression of emotion (of a textual expressive speech act)

The following paragraphs will deal with each of these functions in detail; especially since inspection of the data reveals that the same functions are performed in both sets but differing in frequency.

26 The term results from the blending of "emotion" and "icon". Quite correctly, scholars have criticised this denomination as inaccurate (Dresner and Harring 2010), since emoticons do not only serve the function of expressing emotions. 


\subsubsection{Boosting rapport}

A major function of social networking sites is enhancing or boosting social relationships. Interlocutors often communicate for the sake of it, and the pleasure of being in touch. Boosting rapport specially happens in relation to some speech acts targeted at the addressee's positive face such as other-centred expressives (e.g. compliments, thanking, agreements, greetings, etc.) (Carretero et al. 2014), as illustrated by (6) to (9) below from both datasets:

(6) (ID)

U2 (m): Safe travels! Happy 4th!

U1 (f): Thanks, Noodles. ;)

(7) (ID)

That's right mate!....they are some sexy, badass trainers :)

(8) (TD)

Yes, I agree :D

(9) (TD)

Excellent analysis, Anat! :-)

Boosting rapport can be expressed by means of smileys (as in (7) and (9), winks (6) and laughter (8). In the case of TD, greetings -also rapport boosters- are frequently accompanied by emoji, as illustrated by (10) and (11). Emoji can also appear in combination with other speech acts like thanking (12). Quite curiously, in TD they are not used together with other speech acts apart from greetings (including farewells) and expression of thanks. Further research should zero in on the reasons why these participants restrict emoji to just these two speech acts. As already commented, participants in the ID set do not even use them, probably due to their age difference.

(10) $\mathrm{See} \mathrm{you}^{\wedge \wedge}$

(11) Good night ${ }^{\wedge \wedge}$

(12) thanks a $\operatorname{lot}^{\wedge \wedge}$

Apart from other-centred expressive speech acts, jocular mockery is often resorted to as a rapport boosting strategy (cf. Maíz-Arévalo 2014). Jocular mockery, which involves laughing at oneself and others from a friendly angle, can be reinforced online by means of different emoticons like winks (13), smileys (14 and 15), laughter (16 and 17) and tongue out (18):

(13) (From ID)

U1 (f): Got my lobster roll, finally!

U2 (f): lobster salad at Trump Tower yesterday....just wasn't the same!

U3 (f): how's the impromptu vacation?

U1 (f): Family's taking advantage of me and sent me to Maine to file paperwork. I insisted on a lobster roll as payment. :)

U3 (f): Only one? I think that requires at least a dozen

U1 (f): Well, my dad got the birthday discount. ;) 
In (13), User 1 employs both a smiley to mark the joking mood of her statement -i.e. despite appearances, she is not complaining about her family. This joking mood is taken up by User 3, whose exaggeration ("only one? I think that requires at least a dozen") is met by further joking on User 1's side ("Well, my dad got the birthday discount.").

(14) (TD) However, in the future these readers may become active, especially if they decide to study applied linguistics!! :-)

(15) (ID) Anatomic ones of course... or is it Sainsbury's knicker lines :-)

(16) (TD) We could also say that the prince is looking at Cinderella 'from above'... but it might also be the case that he is simply taller, poor prince :-D

(17) (ID) Is this a fb update it back to Bollywood reunion?? :-D :-D :-D

(18) (ID) Did your sneakers go out? ;p

However and as already commented, there is a remarkable difference in how often interlocutors joke in each dataset. Not surprisingly, in TD where the participants hardly know one another and are communicating primarily to finish a common task, joking is rare whereas Facebook users tend to joke much more often, also given the fact that entertainment is a crucial function played by social networking sites, and joking is entertaining. In other words, boosting rapport in TD is often related to other-centred expressives (e.g. greetings, thanking, agreement, etc.) whilst in ID is more connected to jocular mockery.

\subsubsection{Saving face strategies}

Prior research has revealed emoticons can also function as face-saving strategies (cf. Darics 2010; Golato and Taleghani-Nikazm 2006; Dresner and Herring 2010). As already mentioned, they can be targeted both at saving the speaker's or the addressee's face, or both simultaneously. Quite commonly, face-saving strategies are aimed at saving the interlocutor's face when the speaker performs a face-threatening act (Brown \& Levinson 1987). This is the case of speech acts such as directives, where the speaker demands a future action from the interlocutor (Searle 1969). In fact, directives are often accompanied in both datasets by an emoticon softening the face-threat, as in the advice in (19), taken from ID or the request in (20) from TD:

(19) You should go and enjoy a good run... will feel a lot better afterwards :)

(20) Please let me know what you think about these issues and then maybe we could go on with the other images. :-)

Suggestions can also be argued to belong to this category of directives, since the speaker is presenting a possible path for the addressee to follow. Suggestions might seem less face-threatening than other directives since the speaker is far from forcing the addressee to do something rather than to consider a possible way to act. However, inspection of the 
data reveals that they are often accompanied by face-saving emoticons. Given the nature of the task, suggestions are especially frequent in TD, as illustrated by (21) to (23) below ${ }^{27}$ :

(21) This may simply show that it was love at first sight :D

(22) Again, this is just a suggestion.;-)

(23) but this might be complete nonsense!! :-D)

When the speech act threatens the speaker's face, it seems to be often accompanied by an emoticon, being smileys the most versatile ones. A case at hand is that of apologies, which are especially face-threatening both for the speaker (who admits having made a mistake) and the addressee (who may be directly affected by this mistake in a wrong way). Examples (24) and (25), taken from ID and TD respectively, illustrate an explicit and an implicit apology:

(24) sorry for my english [sic]! :)

(25) Yes, I haven't included in the first two set of images any of the things we mentioned in Task 3 :-)

Apart from apologies, other speech acts that may be face-threatening for the speaker are self-centred expressives, insofar as they "publicise" what might be inner emotions of the speaker, not easily shared. The semi-public nature of Facebook, for example, renders these acts especially face-threatening, which might explain why they are often accompanied by 'softening' emoticons. In the case of TD, it could be argued that the task at hand may favour other-centred expressives but not self-centred ones. Emoticons frequently used to repair possible face-threat to the speaker are smileys (the most versatile one) and laughter. Example (26) from TD shows the writer's concern, in (27) from ID the author expresses her hopes and wishes. Finally, (28) is interesting since the speaker seems to be minimising her boasting that she is leading an exciting lifestyle:

(26) I'm just a bit worried because the document is 10 pages (though it includes many tables) $:-) \ldots$

(27) so lets hope I can study something I'll enjoy! :D

(28) I wish I was able to come back to Madrid soon, I'm missing it so much!! ...but I'm leaving for the states in 3 weeks!! crazy! :)

Quite remarkably, the use of emoticons as face-saving strategies seems to be rather similar in both datasets (25\% in ID and $35 \%$ in TD). However, a closer look at the data reveals an interesting difference. Thus, Facebook users in ID seem to opt for face-saving strategies targeted at saving their own (the speaker's) face whereas participants in the transactional corpus favour saving their interlocutor's face. This inversely proportional

27 No example of suggestions was found in IC, which might be simply due to the limitations in size of the sample. 
difference is illustrated by Graph 1 and can be due to two factors: on the one hand, the semi-public nature of Facebook, where speakers might need to safeguard their own face more carefully in the ignorance of who might eventually be reading their comments. On the other, the lack of closeness between the participants in TD, who might lead them to act more cautiously towards their partners so as to endanger neither the success of the collaborative task at hand nor the possibility of a closer relationship.

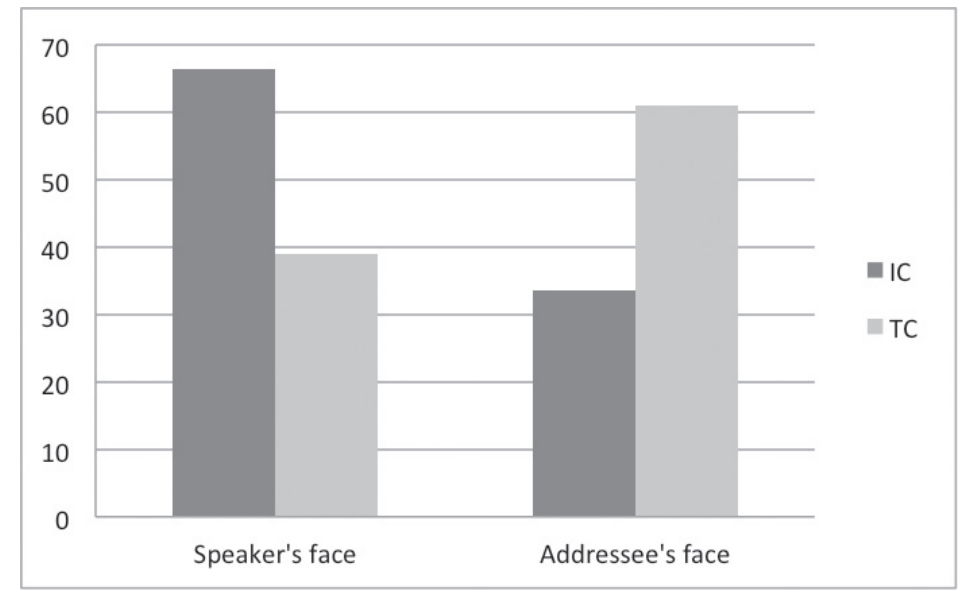

Graph 1. Face-saving strategies in both datasets

\subsubsection{Enhancing the expression of emotion}

As their name misleadingly suggests, emoticons are the icons used in computer-mediated communication to express emotion. Indeed, this is one of their functions but, as previously shown far from the only one. The expression of emotion is often linked to selfcentred expressive speech acts, where the speaker voices an inner feeling or state of mind, as in (29) and (30) below, from ID and TD respectively. In (29), user 1 has posted a photo of her cat inside a box, followed by another user's expression of tenderness:

(29) awww, [Cat's name] ;)

In (30), the addresser interrupts her collaborative work to simply express her happiness that it is snowing and how thrilled she feels. Quite interestingly, this expressive speech act occurs at the very end of the forum, when participants seem more comfortable to start opening up in front of their partners.

(30) AH, and it's snowing :D:D It's sooo beautiful:D

However, this function -i.e. using an emoticon to express emotion can frequently overlap with the other two: boosting rapport and saving face. In the first case, 'opening 
up' in front of our interlocutor can lead to a greater rapport with them (and their reciprocal opening up too). In the second case, a speaker may be protecting hers or her interlocutor's face whilst simultaneously expressing her own feelings. The coming examples illustrate this overlap. Thus, (31) shows the addresser's excitement about her friend's coming visit, which not only serves to express her positive emotion but also boosts rapport between both friends. In (32), the addresser's sadness reinforces her sympathy towards the addressee's accident - i.e. she has recently broken her leg and posts a picture of her cast. In TD, one of the participant's personal preferences (33) is almost immediately followed by another participant's agreement (34), which proves revealing inner feelings can indeed help boost rapport and vice versa.

(31) love you too! and counting the days :-)

(32) Ow! That's not good :-(

(33) This is why my favourite cartoon is Mulan hehe :D

(34) By the way, I also prefer Mulan hehe :-)

The overlap [emotion and face-saving strategies] is slightly less frequent but occasionally found -e.g. in apologies as in (35), already quoted as (4) but repeated here for the sake of clarity:

(35) I went looking for the GLOBE in the rain and got lost! Sorry to miss it :-(

Not surprisingly, however, the expression of emotions occurs more frequently in ID, where $25 \%$ of the emoticons are used in this sense (exclusively or in combination with any of the other strategies) versus just $4.5 \%$ of the cases in TD.

\section{CONCLUSIONS}

This paper has tried to answer the following two research questions, repeated here for the sake of clarity: (i) Are emoticons used as much in interactional as in transactional CMC encounters? And (ii) Do they perform the same functions? To this purpose, two datasets were compared: one whose main communicative target was interaction and the other whose goal was more transactional than interactional. With regard to the frequency of use of emoticons, it was hypothesised that they would be more frequent in the interactional than the transactional corpus. However, and contrary to expectations, the number of emoticons in the transactional dataset almost tripled that of the interactional one. This might have been due to the fact that the forum was a more private place as opposed to the semi-public nature of Facebook, to the different age of the participants (with those of the transactional dataset belonging to a younger generation) and to the need of the latter to boost rapport so as to succeed in their collaborative task.

Regarding the second question, it was theorised that emoticons would perform different pragmatic functions. Inspection of the data revealed that there were three major functions performed; namely, boosting rapport among interlocutors, as face-saving strategies and as 
expressions of emotions. Although the three functions were present in the three datasets, it was however observed that the frequencies were different.

Boosting rapport predominated over the other two functions -i.e. face-saving and expressing emotions -in both datasets. In the case of the interactional set, boosting rapport can be argued to be the raison d'être of social networking sites, which may explain its high frequency. As for the transactional set, and given that the participants did not know one another well enough, a good rapport was indeed advisable to succeed in their collaborative task (cf. also Carretero et al, 2014). With regard to face-saving strategies, they were slightly more common in the transactional corpus, although a curious difference was observed. Thus, whilst participants in the transactional set tended to safeguard the addressee's face rather than their own; in the case of the interactional set, it was exactly the opposite, with addressers trying to save their own face. Finally, and not surprisingly, the expression of emotion was more frequent in the interactional set, where participants may feel more prone -given the nature of the social networking site -to share their feelings and emotions. Quite curiously, the expression of emotions was not totally absent in the transactional set and even increased by the end of the forum, once rapport had been built among the participants. Graph 2 sums up these results:

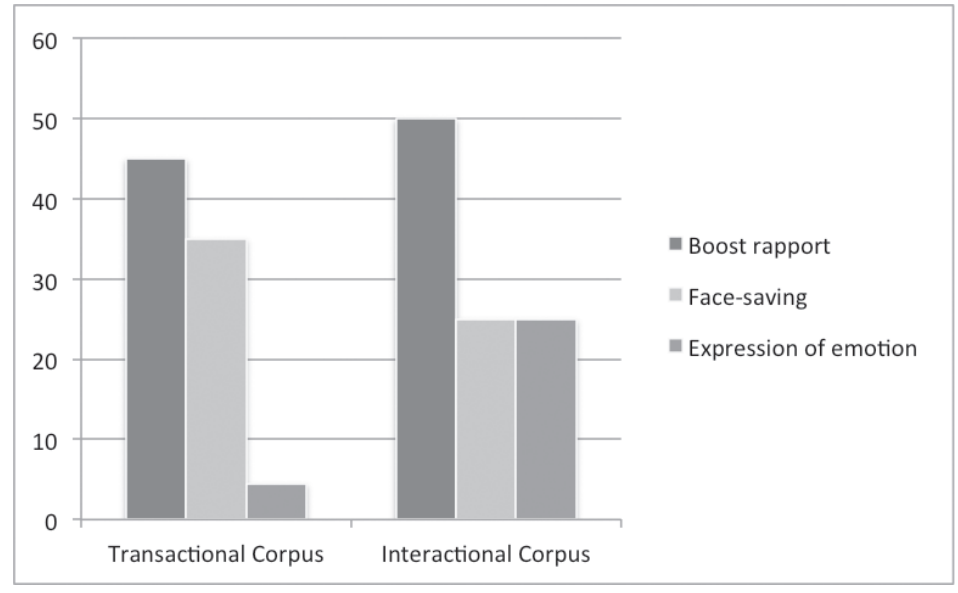

Graph 2. Pragmatic functions of emoticons in both datasets

There are some important limitations to this study that need acknowledging. Both corpora include only female participants, even though the gender variable has been proven to influence the function emoticons can play (Baron 2004; Huffaker and Calvert 2005; Lee 2003; Maíz-Arévalo 2014; Wolf 2000). Admittedly, this is a serious limitation of the present study. However, it also permits to unify the gender variable. Another major limitation is size, being both datasets not big enough to reach general conclusions but mere approximations to some trends. Future research on a larger corpus is needed to find out whether these trends can indeed be generalised. 


\section{REFERENCES}

BARON, N. S. 2004. "See you Online Gender Issues in College Student Use of Instant Messaging". Journal of Language and Social Psychology 23, IV: 397-423.

BROWN, G. \& G. YULE. 1983. Discourse analysis. Cambridge: Cambridge University Press.

CARRETERO, M., C. MAÍZ-ARÉVALO, C. AND MARTÍNEZ MARTÍNEZ, M.A. 2014. "'Hope this helps!' An analysis of expressive speech acts in online taskoriented interaction by university students." Yearbook of Corpus Linguistics and Pragmatics 2014: New Empirical and Theoretical Paradigms. Ed. J. Romero Trillo. Berlin: Springer and Verlag. 261-289.

CRYSTAL, D. 2001. Language and the Internet. Cambridge: Cambridge University Press.

DARICS, E. 2010. "Politeness in computer-mediated discourse of a virtual team." Journal of Politeness Research 6, I: 129-150.

DERKS, DAANTJE, E.R. ARIJAN E.R. BOS AND J. VON GRUMBKOW. 2004. "Emoticons and social interaction on the Internet: the importance of social context". Computers in Human Behaviour 23: 842-849.

DERKS, DAANTJE, AGNETA H. FISCHER AND ARJAN E. R. BOS. 2008. "The role of emotion in computer-mediated communication: A review". Computers in Human Behaviour 24: 766-785.

DRESNER, E. AND S. C. HERRING. 2010. "Functions of the Nonverbal in CMC: Emoticons and Illocutionary Force". Communication Theory 20: 249-268.

FOX, A. B., ET AL. 2007. “The Medium Makes a Difference Gender Similarities and Differences in Instant Messaging”. Journal of Language and Social Psychology 26, IV: 389-397.

GOLATO, A. AND C. TALEGHANI-NIKAZM. 2006. "Negotiation of face in web chats". Multilingua-Journal of Cross-Cultural and Interlanguage Communication 25, III: 293-321.

HANCOCK, J.T. 2004. "Verbal irony use in face-to-face and computer-mediated conversations." Journal of Language and Social Psychology 23, IV: 447-463.

HAUGH, M. \& D. BOUSFIELD. 2012. "Mock impoliteness, jocular mockery and jocular abuse in Australian and British English". Journal of Pragmatics 44, IX: 1099-1114.

HERRING, S. C. 2003. "Computer-Mediated Discourse." Handbook of Discourse Analysis. Eds. D. Tannen, D. Schiffrin and H. Hamilton. Oxford: Blackwell. 612-634.

HUFFAKER, D. A. AND S. L. CALVERT. 2005. “Gender, identity, and language use in teenage blogs". Journal of Computer Mediated Communication 10, II: 00-00. 
KOZINETS, R. V. 2010. Netnography: Doing ethnographic research online. London: Sage Publications.

LEE, C. 2003. "How does instant messaging affect interaction between the genders." Stanford, CA: The Mercury Project for Instant Messaging Studies at Stanford University. 11 October. 2013. http://web.stanford.edu/class/pwr3-25/group2/pdfs/ IM_Genders.pdf

LO, S. K. 2008. "The nonverbal communication functions of emoticons in computermediated communication". CyberPsychology \& Behavior 11, V: 595-597.

MAÍZ-ARÉVALO, C. 2014. "A pragmatic and multimodal analysis of emoticons and gender in social networks.” Academia.edu. 30 November. 2014. https://www. academia.edu/Documents/in/Emoticons

MAÍZ-ARÉVALO, C. 2012. “"Was that a compliment?' Implicit compliments in English and Spanish". Journal of Pragmatics 44, VIII: 980-996.

MAÍZ-ARÉVALO, C. 2013. "Just click 'Like"': Computer-mediated responses to Spanish compliments". Journal of Pragmatics 51: 47-67.

MAÍZ-ARÉVALO, C.AND C. SANTAMARÍA GARCÍA. 2013. "Hibridismo entre el lenguaje oral y escrito". Cuadernos Hispanoamericanos. Dossier: Cultura y nuevas tecnologías, 761: 69-85.

SEARLE, J. R. 1969. Speech acts: An essay in the philosophy of language. Cambridge: Cambridge university press.

YUS, F. 2011. Cyberpragmatics: internet-mediated communication in context. Amsterdam: John Benjamins Publishing.

YUS, F. 2014. "Not all emoticons are created equal.” Academia. 2 December. 2014 https://www.academia.edu/6758152/Not_all_emoticons_are_created_equal 